\title{
12. Experiential ethics education for IT professionals
}

\author{
Ian Stoodley, Christine Bruce and Sylvia Edwards \\ Queensland University of Technology
}

This chapter presents a new approach to IT ethics education that may be used by teachers in academic institutions, employees responsible for promoting ethics in organisations and individuals wanting to pursue their own professional development. Experiential ethics education emphasises deep learning that prompts a changed experience of ethics. We first consider how this approach complements other ways of engaging in ethics education. We then explore what it means to strive for experiential change and offer a model which may be useful in pursuing IT professional ethics education in this way.

\section{Different ways of approaching IT ethics education}

Since education may be thought of in different ways, we need to be clear that the term 'education' is used here in a broad sense. Education is thought of here as any space where learning or personal development takes place. It may thus involve formal training, informal assistance or personal retreat. It may occur in pre-service formation or in-service courses, in organisational and private contexts, or within the walls of educational institutions.

The prevailing approaches to IT ethics education are characterised in this chapter as:

1. exercising behavioural control

2. developing decision-making skills

3. developing moral sensitivity.

Our additional approach, experiential ethics education, may be characterised as:

4. prompting new experiences. 


\section{Ethics education seen as exercising behavioural control}

\begin{tabular}{|c|l|}
\hline $\begin{array}{c}\text { Hypothetical } \\
1\end{array}$ & $\begin{array}{l}\text { Carol Anderson, CEO of Ventures in IS, wants to influence her employees } \\
\text { towards deeper ethical action. In consultation with the management } \\
\text { team, she adopts the Australian Computer Society (ACS) code of ethics, } \\
\text { requires employees to sign a statement agreeing to abide by this code } \\
\text { and runs periodic training sessions that highlight aspects of the code. }\end{array}$ \\
\hline
\end{tabular}

When ethics education is considered to be exercising behavioural control, the emphasis is on instilling authorised standards. For this reason, codes of conduct figure prominently in this approach and the predominant technique utilised is the presentation and enforcement of such codes. Codes have been found to be useful instruments to a) enable action to be taken in response to a complex ethical issue within a reasonably short period of time, b) help introduce some objectivity into the decision-making process, and c) serve as a guide for people who are not trusted to make a valid choice independently (Colnerud, 2006). The promotion of codes of conduct is considered to exert an influence on attitude, which has been identified as influencing intention, which in turn influences behaviour. Codes, therefore, are a valid element of ethics education whose aim is to ensure conformity to institutional standards (Cronan \& Douglas, 2006; Leonard, Cronan \& Kreie, 2004).

\section{Ethics education seen as developing decision-making skills}

\begin{tabular}{|c|l|}
\hline $\begin{array}{c}\text { Hypothetical } \\
2\end{array}$ & $\begin{array}{l}\text { Dan Glover, national sales manager for an international company } \\
\text { providing IS services to businesses, is concerned that employees are } \\
\text { able to respond ethically in a rapidly changing environment. He engages } \\
\text { a training institute to develop workshops based on Leonard Kohlberg's } \\
\text { stages of moral development, to help employees in their on-the-spot } \\
\text { decision-making when interacting with clients. }\end{array}$ \\
\hline
\end{tabular}

When ethics education is considered to be developing decision-making skills, the emphasis is on cultivating individuals who are able to take independent decisions about moral issues. Kohlberg's stages of moral development are typically referred to in this context. Kohlberg proposed six developmental stages:

1. avoidance of punishment

2. seeking reward or benefit

3. avoidance of others' disapproval

4. avoidance of dishonour

5. respect for people

6. desire to not violate personal principles.

(Kohlberg, 1981: 121-22) 
These stages emphasise rational thinking and judgement, and tend to esteem an intellectual and critical approach to norms. They promote independence, logic and universal principles.

This approach to ethics education focuses on logical ethical processes and is synonymous with training in decision-making (Maner, 2004).

\section{Ethics education seen as developing moral sensitivity}

\begin{tabular}{|c|l|}
\hline $\begin{array}{c}\text { Hypothetical } \\
3\end{array}$ & $\begin{array}{l}\text { Andrew Davis, academic in the IT Faculty of the University of Northern } \\
\text { Queensland, wants to sensitise students to IT ethical issues. He } \\
\text { prepares a number of case studies, which are integrated into his course. } \\
\text { The students discuss the ethical implications of these in small groups, } \\
\text { present the issues and their conclusions to the larger class, and the } \\
\text { class responds. }\end{array}$ \\
\hline
\end{tabular}

When ethics education is considered to be developing moral sensitivity, the emphasis is on imbuing an ethical outlook in individuals.

Moral sensitivity is reflected in Carol Gilligan's care approach to moral development, which focuses on the relational, contextual and enacted aspects of ethics (Tronto, 1993). Gilligan proposed the developmental stages of:

1. exclusive self-concern

2. questioning of self-concern as a sole criterion

3. balanced self-and-other concern.

(Gilligan, 1982)

These stages are understood by some to be accommodated by James Rest in a 'Defining issues test' which has been employed in a number of IT ethics studies (for example, Paradice \& Dejoie, 1991; Staehr \& Byrne, 2003; Woodward, Davis $\&$ Hodis, 2007). This test identifies four aspects of ethical behaviour, with a view to offering a comprehensive representation of the requirements for moral behaviour:

1. Sensitivity - ethical awareness of the existence of an issue requiring a moral response.

2. Judgement - Kohlberg's stages of development.

3. Motivation - reconciliation of conflicts between moral demands and personal goals.

4. Character - a willingness to pursue moral behaviour, despite difficulties.

(Rest, Narvaez, Bebeau, and Thoma, 1999) 
According to this approach to ethical education, students of ethics are more than functional skill-bearers and must be approached as whole human beings who need to be influenced at the level of their values and ideals. Only by attending holistically to the professional, will ethics become integrated in a coherent way into their lives. In organisational settings many personal traits associated with ethical conduct (for example, compassion, generosity and idealism) may be suppressed rather than encouraged (Goodpaster, 1996). Professionals who wish to be ethical in this context need to be able to discern what is ethical, independent of their environment.

The development of a core disposition of responsibility is thus recognised as integral to professional ethics formation. This is expressed as ethical sensitivity (Grodzinsky, 1999), a readiness to engage in moral deliberation (Tavani, 2004), having a moral horizon (Grodzinsky, 2000) and a commitment to moral action (Coady \& Bloch, 1996). Thus, 'good ethical judgement' forms the basis for ethical analysis and constitutes the core need of IT professionals (Bynum, 2004). This is ultimately gained through experience, however, heuristic methods of analysis (based on pattern recognition more than formal logic) are suggested aids to the process. This ability may be developed through case analysis.

We suggest that these three approaches to IT ethics education are increasingly powerful. Exercising behavioural control focuses on the standards for ethical practice and aims at producing compliant professionals who understand the expectations of external authorities to whom they are accountable. Developing decision-making skills focuses on the method of ethical deliberation and aims at producing logical professionals who know techniques of reasoning about ethical dilemmas. Developing moral sensitivity focuses on the necessary attitude of ethical responsibility and aims at producing responsive professionals who are discerning of ethical issues in the course of their practice.

Each of these builds on the former and enhances it. Compliant professionals require clear guidance concerning how to act in the specific circumstances that they may face and tend to approach ethics as the avoidance of harm rather than the pursuit of good. Logical professionals can apply standards to new situations and generate their own understanding of the good in situations, however their readiness to engage in reflection depends on their propensity to be ethical in the first place. Responsive professionals are attuned to ethical possibilities and are thus alert to apply reflective skills in accordance with ethical standards.

These approaches emphasise respectively content, process and motivation, and thus focus on different aspects of professional ethical practice. Rather than suggesting that any one of these should be abandoned, it would seem that a comprehensive educational approach would encompass all of them. We now turn to another approach to ethics education, which has not yet been explored 
extensively in the IT ethics literature but which may also be usefully applied. This approach focuses on the need to bring about a new kind of learning, which is based on variation of experience. Learning ethics in this approach is defined as becoming aware of ethics in a different way.

\section{Ethics education seen as prompting new experiences}

\begin{tabular}{|c|l|}
\hline $\begin{array}{c}\text { Hypothetical } \\
4\end{array}$ & $\begin{array}{l}\text { Carol Simons, personnel director of a national software development } \\
\text { company, calls a series of roundtable meetings of employees, } \\
\text { management, clients and other stakeholders. At these meetings each } \\
\text { group is invited to contribute their understanding of ethics as it applies } \\
\text { to the company. Together they produce a joint expression of the } \\
\text { organisation's ethics, in diagrammatic and prose form. }\end{array}$ \\
\hline
\end{tabular}

When ethics education is approached as prompting a new experience of ethics, the emphasis is on stimulating individuals to change their conception of ethics. Their future actions will then flow from these new conceptions. Therefore, from this perspective, educational experiences should be designed to provide a lasting impact on the learner at a personal level, engaging learners in fundamental ways. We suggest that this approach provides a foundation upon which the approaches outlined earlier may build. The strength of this approach lies in its promotion of reflective, deep and authentic learning.

\section{Promoting reflective learning}

Such an approach is called a relational, in contrast to a cognitive or behavioural, approach to learning. That is, to stimulate learning we show the interrelationship of the different facets of ethical experience and prompt interaction with these facets. The central role of reflection and communication needs to be recognised and incorporated into the learning experience.

Relational learning may be summarised by the following key features (Ramsden, 1988: 26-28), together with their suggested application to ethics formation:

1. Promoting conceptual change. Learning is about changes in conceptions a fundamental change of engagement with ethics is more important than knowing philosophical schema, decision-making techniques or arguments surrounding a specific issue.

2. Learning always has content as well as a process - engagement with actual ethics scenarios is more productive educationally than addressing process questions without also giving attention to the ethical content.

3. Improving learning is about relations between learners and subject matter, not teaching methods and student characteristics — the personal engagement 
of learners with ethics is more important than how the content is conveyed or what learning styles are represented.

4. Improving learning is about understanding the student's perspective - the learner's existing engagement with ethics is the starting point from which instruction may begin.

This approach, succinctly summarised by Ramsden 20 years ago, was originally developed from Swedish research and has been communicated in detail to the university sector through two important titles, Learning and awareness (Marton \& Booth, 1997) and The university of learning (Bowden \& Marton, 1998).

The approach highlights the difference between knowing something intellectually and effective learning. The goal of teaching thus changes from the transmission of facts to the stimulation of personal engagement with the phenomenon. It recognises the IT professional as an integrated human being, rather than simply a physical, mental or emotional entity. It privileges the professional's viewpoint as the foundation for ethical instruction.

\section{Promoting deep learning}

Attention is drawn in the IT literature to questions concerning the quality of learning that is achieved in the ethics curriculum. The difference between deep and surface learning is highlighted by these questions and the key to this difference lies in the extent to which students engage personally with the course content. Shallow learning may be evidenced by the students distancing themselves from personal ethical engagement and adopting an uncontested selfdefining approach to ethics.

One danger for students who adopt a 'shallow' approach to ethics education is that they risk disowning the content by externalising it and, for example, equating it with law ... a 'shallow' approach to learning might equally result in a reduction of the content to a matter of opinion, a state of solipsism in which ethical dilemmas are completely addressed by internal dialogue. (Greening, Kay \& Kummerfeld, 2004: 93)

Consideration, therefore, needs to be given to 'valued learning' in the context of ethics education. In a relational approach, learning will focus on those aspects of the object of learning (in this case, professional ethics) which are qualitatively and critically different, in order to bring about wider awareness. 


\section{Promoting authentic learning}

Seen this way, instruction needs to be more than the teaching of rules, the presentation of simple scenarios and reactions to dilemmas. Each of these may result in a particular (and unhelpful) way of viewing IT ethics, including externalising ethics, equating being legal with being ethical, oversimplifying solutions and failing to take a proactive stance towards ethics. In order for professionals to take ethics seriously and be equipped to practice ethics in more than superficial ways, they need to be engaged at a personal level. A greater emphasis, therefore, needs to be placed in IT ethics education on the authenticity of learning tasks and lifelong learning (Greening et al., 2004).

Such an approach to learning does not allow the learners to avoid the question of having to change their fundamental understanding (Ramsden, 1988). This engagement with the course content cannot be achieved through simple instruction - the learner has to interact with the content on an experiential level.

... teaching methods that enable students to work on discrepancies in a supportive environment - one that permits incorrect thoughts to be retraced and remedied - are likely to be appropriate. Simply telling students the 'right' conception cannot work, because change involves an active working upon and interaction between the old way of thinking and the new; there is a real sense in which new conceptions grow from older ones. Change in conceptions requires teachers to arrange situations where students must confront the discrepancies between their present way of thinking about the subject matter and the new way desired by the teacher, and where students can come to realize the personal value of the new way. This realization may take a very long time to mature. Time for contemplation, reflection, working things out, and discussion with others learning the same subject matter is thus not a luxury, but a necessity. (Ramsden, 1988)

\section{Elaboration of an experiential approach to ethics education}

The primary goal of the educational approach we are advocating, then, is to promote a change of experience. Promoting a change of experience is understood to be more than introducing the learner to new knowledge or drilling them in new behaviour. It is instead about establishing a new relationship between the learner and the object of their learning. In this relational approach the learner addresses the qualitatively significant aspects of the phenomenon and incorporates them into their world. New understanding and comportment result from such change. 
Various words or phrases are used here to express the idea of 'experience'. Conception, understanding, view and way of seeing are all synonyms. These indicate the relationship between a subject (here IT professionals) and the object of that subject's attention (here ethics).

The idea of experience as used here can be understood by contrasting two alternative approaches to knowledge. According to one approach, reality is separate from the individual and knowledge is gained by the individual being aligned with this external reality. This objectivist approach is dualistic, whereby the individual and reality are distinct from each other. According to the other approach, reality is intimately connected to the individual and knowledge is gained by the individual's construction of meaning. This is a constructivist approach, whereby the individual determines the meaning of reality (Svensson, 1997).

The relational approach understands that the individual and reality are distinct but intimately related. Even though there is an external reality, humans always interpret that reality through their experience. The subject (the one experiencing) stands in relation to the object (the phenomenon which they are experiencing), with each (both subject and object) contributing to the experience. This is a constitutionalist (or interpretive, or relational) approach, whereby meaning is constituted by the interaction of subject and object (Bruce, 1997; Ramsden, 2003; Trigwell, 2000). Knowledge is the developing relation between the individual and reality.

Building on a constitutionalist view of knowledge, learning is defined as a change of experience, rather than being simply cognitive or behavioural (Ramsden, 1988). Education is therefore about stimulating a change in the way a person (in this case, an IT professional) relates to a phenomenon (in this case, ethics). The learner's personal engagement with and understanding of the relevance of the phenomenon are integral to this approach. The retention of facts or mastery of processes may be expected to result from, but are peripheral to, the aims of such an education.

The nature of learning is presented here as constitutionalist rather than cognitivist. A change from a cognitivist to a constitutionalist approach requires a re-evaluation of the nature of knowledge and the goals of education. Learners, according to a cognitivist approach, 'are supposed to learn the truth and reproduce it in tests', so that, when they begin a non-cognitivist course, they have to learn again what it means to learn and to 'construct their own answers and be critical' (Stahl, Wood \& Howley, 2004: 13). Instead of just learning to reproduce vocabulary and arguments from 'authoritative' sources, learners are expected to engage with the material and develop their own understanding. 
Professional bodies and employers rely heavily on authoritative sources, such as codes of ethics, to provide a standard of conduct for their members and employees. A reliance on unmediated codes and regulation may indicate that a cognitivist approach is being adopted. Such an approach assumes that:

1. Reality is independent and separable from humans.

2. Reality is objective, and its qualities and meaning are inherent to itself.

3. Language corresponds directly to objective reality.

4. Causal relationships explain human behaviour.

5. Human behaviour has inherent characteristics and is independent of particular situations.

6. Humans are bound by their circumstances to act in a particular way.

In contrast, a constitutionalist perspective believes that:

1. Reality and humans are inseparably related through the individual's experience. People behave under the influence of their experience of the world, not outside of it.

2. People's understanding of reality is constructed through their own experience and through their interactions with others.

3. People's actions are controlled by their interpretation and understanding of a situation. This includes their ideas about: the 'facts' and their alternatives; other people's feelings, intentions, expectations and reactions; and what is right and wrong, and appropriate.

(Sandberg \& Targama, 2007: 22-30)

In the light of these observations, a constitutionalist stance does not assume that statements of standards in codes will be understood in the same way as they were authored, or that regulation will be interpreted in the same way as it was intended. Knowledge formation is understood to be highly communicative and dependent on specific circumstances.

Therefore, communication about ethics is most effectively conducted in the professional's particular circumstances and, most usefully, pursues those issues that are experienced as valuable by the professional in those circumstances. In the light of the difficulties faced by professionals in the organisational setting (for example, standing up to those who control the provision of their basic needs) such conversations about ethics are most realistically initiated and maintained by the organisational leadership, to achieve the 'legitimation of moral discourse as a voice in the professional and managerial conversation' (Goodpaster, 1996: 445). 
We are not suggesting here that standards as expressed in codes are no longer needed. Since professionals interpret these guidelines based on their experience, however, complementary means are required to make the codes effective as guides for conduct. Conversations about codes would start from the professional's perspective and seek to see ethics from their point of view. They then would introduce the professional to new ways of seeing ethics (in conformity with the code), with a view to widening their experience.

Another approach employed in IT ethics education has been to emphasise decision-making. This aims at producing independent thinkers. A reliance on the internal processes of the individual, and emphasis on critical thinking and problem-solving, may indicate that a constructivist approach is being adopted. This presumes that individuals have the capacity in themselves to discern what is ethical.

The constitutionalist approach, in contrast to cognitivist or constructivist approaches, emphasises not just the environment external to the learner or just the internal functioning of the learner, but the relation between these. Both of the external and internal aspects are seen as contributors, exerting an influence on each other.

A constitutionalist understanding of knowledge formation, for example, deduces that ethical support will not be effective if approached in a top-down managerial style (Sandberg, 1994). Management following a constitutionalist method would start from an understanding of ethics as seen through the eyes of employees, then seek to build a shared meaning of ethics in their specific organisational context. Working collaboratively with employees, they would arrive at an understanding of ethics constituted from both their perspective and the employees' perspectives. This requires a longer time and energy commitment than a directive approach, however, it is suggested it would be more effectual in achieving an ethical outcome. It also proposes a moral means of promoting ethical practice by valuing employees and their perspectives, and could provide a platform to respond to the concerns of IT professionals (for example, about profit-making in business) (Stoodley, 2009b).

The following ideas serve to indicate the kinds of support that may be offered from a constitutionalist perspective.

1. Since IT professionals see ethics in terms of relationships, one such means may be to clarify the connection of a code with real human interactions. This could be achieved by presenting exemplary scenarios in conjunction with the code's articles. It is of note that this is offered by some professional bodies, for example the ACS (ACS, 2004; Ferguson, Salmond, Al-Saggaf, Bowern \& Weckert, 2005). 
2. Since a code presumes a prior ethical orientation, another such means may be to promote other-centred attitudes on the part of the employees. This could be achieved by including ethical formation, based on the citizenships revealed in this study, in employees' ongoing professional development.

3. Since ethical guidelines are open to the kind of interpretation that relies on professionals' previous experience, another such means may be to examine the extent to which the code aligns with professionals' perspectives. This could be achieved by a study similar to this project or through tools developed out of this project. This would provide a means of understanding how professionals differ from the expected standard and provide a basis from which to develop learning experiences.

4. Since understanding is constituted rather than simply received, another means may be to embark on a collaborative process of ethical meaningmaking. This may result in a rewriting of organisational guidelines, to reflect the broader perspective. Such collaboration could involve stakeholders at all levels of the organisation's operations.

Integral to these suggestions is the goal of changing a professional's relationship with ethics, rather than simply striving for a change in memorised knowledge or drilled behaviour. A professional's previous experience is not considered 'wrong', rather, it is viewed as incomplete. The purpose of formation and support activities is to expand on, rather than replace, their experience. In this way, a professional's experience of ethics is stimulated to become more comprehensive.

\section{A comparison of the approaches to IT professional ethics education}

What we propose here, then, is an approach to IT professional ethics education that focuses on the relationship of the practitioner to ethics, bringing about experiential change. When a practitioner experiences themselves as being an ethical professional, as portrayed below, they will see themselves and their world differently and, we propose, that this will affect their practice. This is a relational (or constitutional) approach to education that draws on existing educational research. Its originality lies in the fact that it has not previously been pursued extensively in IT ethics education.

The way this approach differs from the alternatives reviewed earlier is summarised in Table 1. When ethics education is approached as Exercising behavioural control, the educational focus is on standards (for example, codes 
of ethics), the educational intention is to produce conformity (for example, according to organisational expectations) and the educational act is presentation (for example, external standards which must be known).

\section{Table 1: Comparison of approaches to IT professional ethics education}

\begin{tabular}{|l|l|l|l|}
\hline Educational approach & Focus & Intention & Act \\
\hline Exercising behavioural control & Standards & Conformity & Presentation \\
\hline Developing decision-making skills & Problem-solving & Reflective thought & Enquiry \\
\hline Developing moral sensitivity & Attitude & Engagement & Heuristics \\
\hline Pursuing a new experience of ethics & Experience of ethics & Changed experience & Challenging experience \\
\hline
\end{tabular}

Source: Author's research

When ethics education is approached as Developing decision-making skills, the educational focus is on problem-solving (for example, methods of decisionmaking), the educational intention is to produce reflective thought (for example, critical thinking) and the educational act is enquiry (for example, posing questions rather than answering them).

When ethics education is approached as Developing moral sensitivity, the educational focus is on attitude (for example, from a psychological perspective), the educational intention is to produce engagement (for example, personal moral sensitivity) and the educational act is heuristics (for example, exposure to many cases in order to recognise patterns).

In contrast, when ethics education is approached as Pursuing a new experience of ethics:

1. The Focus on the experience of ethics recognises the need for the practitioner to grow in their relationship with ethics before they will engage with others ethically. For example, they may need to change from an experience of professionalism bounded by a traditional view of IT that admits little room for consideration of the information user (Stoodley, 2009b).

2. The Intention of a changed experience recognises the need for education to focus on experience as the basic unit of its engagement. For example, practitioners may be more effectively influenced by prompting them to reflect on their approach to the information user rather than requiring them to learn lists of regulations.

3. The Act of challenging experience recognises the need to promote a change in the practitioner's existing experience. For example, stimulating practitioners to extend their experience beyond that which they currently take for granted. 
This alternative approach proposes that the most important goal of ethics education is a change of relationship with ethics, out of which ethical behaviour may flow.

A rationale for the experiential learning of ethics has also been based on the concept of stage disparity (identified by Kohlberg (1981) and Rest (1986)), which makes use of contrast to prompt moral growth (Vartiainen, 2005b). Confrontation with this experience is prompted by solving dilemmas through discussion with others. This provides fertile ground for differences of opinion and exposes the participants to alternative viewpoints. An academia- and industry-based collaborative-learning environment provides the range of experience required to provoke this kind of interaction. Self-criticism and evaluation are used to encourage ethical growth.

The framework broadens the traditional idea of learning professional ethics in an educational institute with hypothetical moral conflicts to a form of experiential learning in which IT professionals together with students critically deliberate about moral conflicts they have confronted in real life ... clients, students, and instructors may be perceived as colearners of professional ethics. (Vartiainen, 2005b: 10)

This approach looks beyond the individual to a community of practice, engaging the IT community in the process of ethical development. It also promotes experiential learning in real contexts.

Suggested teaching methods, reflecting the four aspects of Rest's model, include: moral argumentation and dilemma discussion (for moral sensitivity and judgement); role models and heroes (for moral motivation and character); values clarification (to avoid indoctrination); and logic, role-taking and concept construction (for principled moral reasoning). These methods induce change by presenting individuals with the opportunity to discover inconsistencies in their own thinking, with a view to prompting them to make up their own minds and not accept uncritically what is being presented to them (Vartiainen, 2005a). Thus, a project course is an example of an environment which satisfies the requirements of those who wish to strive to avoid indoctrination, with reliance on experienced practitioners to offer a perspective which aligns with professional standards (Vartiainen, 2005b).

In pursuing a deep-learning outcome, the main aim of our approach is that the student be prompted to have a changed experience of ethics. This, then, is an experience-based approach to learning, which understands learning as a change of relationship, rather than just a change of cognition or behaviour. This moves the focus away from receiving external truth, towards constituting personal 
understanding. Such a change is significant because it shifts professional ethical formation away from an instructor's perspective and moves it to a learner's perspective.

We now present a model which may be a useful tool in approaching IT ethical formation from an experiential perspective.

\section{A model of ethical IT}

A model of IT professionals' experience of ethics is represented diagrammatically in Figure 1. The model combines the experiences of ethics that is found in a group of IT professionals with a representation of an evolving definition of the field of IT. These two aspects are understood to be intimately related. They are also supported in the IT literature and in ethical theory (Stoodley, 2009b).

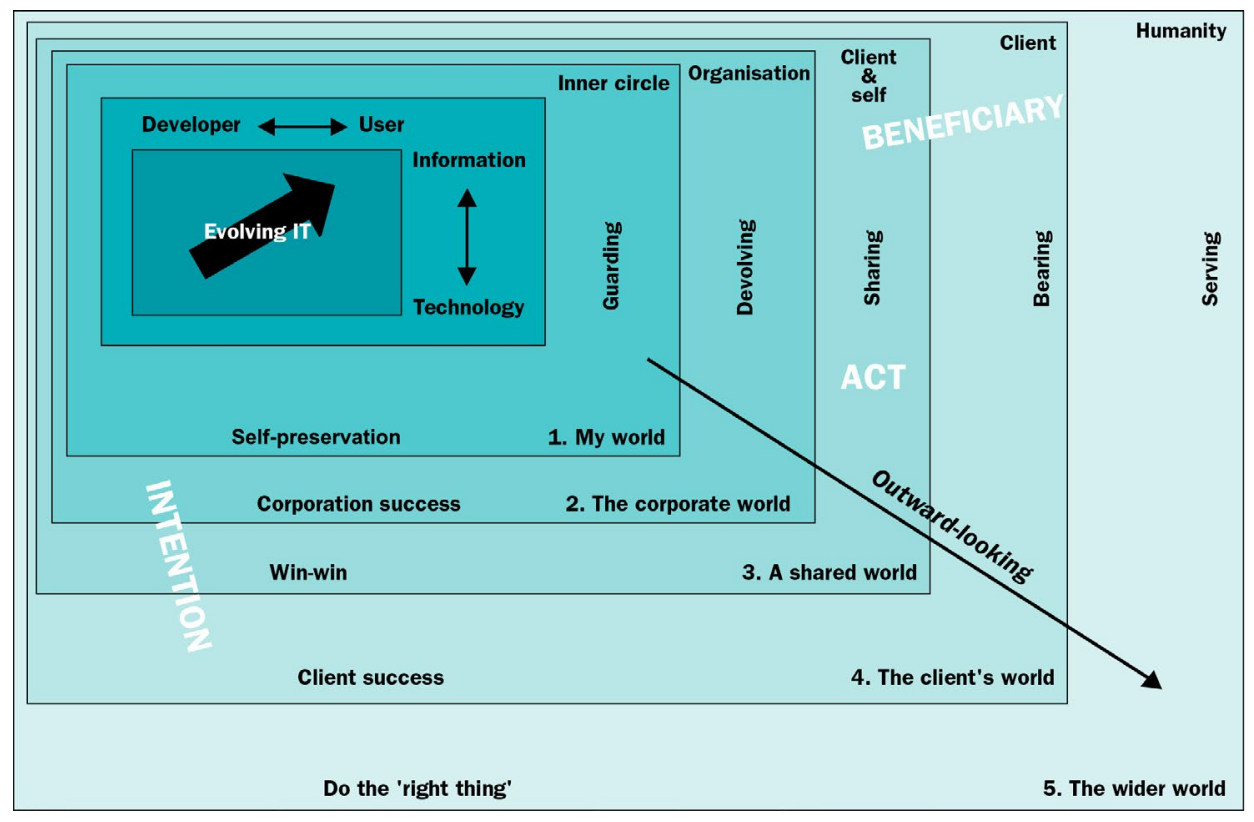

\section{Figure 1: A model of ethical IT}

Source: Author's research

Evolving IT is represented in the model by the innermost rectangles. Acceptance of the evolving nature of the field of IT, towards an increasingly information and user-centred (rather than a technology developer-centred) perspective, is understood as an important aspect of opening IT professionals 
to ethical considerations. It is significant because it moves the focus of IT away from its products and towards its purposes, orienting professionals away from themselves and towards those who are affected by their work.

The 'Model of Ethical IT' illustrates IT professionals' expanding awareness of what it means to be ethical. Five facets of a professional's experience, called 'citizenships', are represented in expanding rectangles which are labelled with the citizenship name in abbreviated form in their rectangle's bottom righthand corner; for example, the second citizenship is called 'Citizenship of the corporate world' and is labelled in the diagram as '2. The corporate world'. Each citizenship, moving outwards from 1 to 5, progressively encompasses the previous citizenships and exerts an influence over them.

The object of ethics is identified as the 'beneficiary' and is included in the model in the top right-hand corner of each citizenship rectangle, for example the organisation being the beneficiary in 'Citizenship of the corporate world'. The activity associated with ethics is identified as the 'act' and is included on the right-hand border of each citizenship rectangle; for example devolving being the act in 'Citizenship of the corporate world'. The underlying objective of ethics is identified as the 'intention' and is included on the lower border of each citizenship rectangle; for example corporation success being the intention in 'Citizenship of the corporate world'. This level of detail serves to show the expanding nature of the experiences as they progress outwards.

The model offers a perspective on how the categories progressively expand outwardly, from a practitioner-centred outlook to a more other-centred outlook. The movement towards greater other-centredness is evident in the change in perspective concerning the beneficiary, act and intention. The beneficiary expands from the professional's inner circle, through the organisation and client, to humanity. The act expands from guarding, through devolving, sharing and bearing, to serving. The intention expands from self-preservation, through corporation success, win-win and client success, to doing the 'right thing'. These increasingly embrace others. The model, then, offers a means of comprehensively conceiving IT professionals' experience of ethics.

The IT professional's experience of ethics may thus be understood to lie along a continuum, with the professional progressively broadening their scope of engagement with others. As a result, they accept that their rights diminish as others' rights are accorded increasing priority, and their responsibility expands as it is defined in terms of others. As the professional's experience of ethics expands, they undergo a dual change of experience, with rights increasingly accorded to others and responsibilities increasingly defined by others' needs. 
Each citizenship in the continuum represents a qualitatively different way of experiencing ethics. Movement into a citizenship that lies further along the continuum signifies a definite experiential change, which crosses a perceptual boundary. The experience of ethics is thus represented in five distinct citizenship categories, along an increasingly other-centred continuum.

The usefulness of the representation of experience in discrete units is its ability to reveal critical differences in experience, which may become objects of our attention, either as reflective professionals or as supporters of professionals. These aspects of ethical experience could otherwise be overlooked and left undeveloped.

The representation here of ethical experience along an other-centred continuum is consistent with the measure of other-centredness presented as an ethical ideal in Stoodley (2009b). Other-centredness recognises the primacy of other people when defining the nature of ethics, in general, and when defining the ground of professional ethics in particular. According to such a view, an ethical perspective places others at the centre of our world, instead of ourselves.

Following this reasoning, the key to understanding the critical differences between the citizenships is the extent to which IT professionals willingly accept that their rights and responsibilities are defined in terms of others. For example, an IT professional may choose to work late in order to complete the testing on a job due to be delivered the next day, rather than simply sign off on the project at the end of the afternoon. The professional thus allows the client's right to receive a properly tested product to limit the professional's own right to a full night's rest. The professional also allows the client's needs to define the scope of their responsibility. Rather than just working the hours required by their employer, the professional accepts the extra hours and allows responsibility for the client to fall on their shoulders. Naturally, we preserve our own welfare, preferring to define our own rights (where we benefit most) and our own responsibilities (where we bear the least responsibility) — taking an ethical perspective challenges both of these attitudes and requires a significant change of perspective.

The progression from 'Citizenship of my world' to 'Citizenship of the wider world', then, represents a dual attitude change, with respect to rights and responsibilities. This change moves from a relatively closed circle of interest and engagement to a more open one. The professionals' awareness of others in their world expands as they move through the citizenships. This is not to imply that 'Citizenship of my world' is unethical, however, increasing recognition of and response to others' needs is understood here to indicate an increasingly 
comprehensive understanding of what ethics is about. From this point of view, an ethically mature IT professional is one who has in their portfolio the full range of citizenships characterised in this account.

It needs to be noted that the citizenships do not represent stages of development but an increasingly sophisticated understanding of ethics. Citizenship 1 is not left behind when a professional experiences Citizenship 2, but their experience of Citizenship 1 is modified by their experience of Citizenship 2 . The citizenship experiences of ethics are thus understood here to be cumulative, so a professional who experiences ethics as 'Citizenship of the wider world' will also experience ethics as all the other citizenships. Each citizenship, however, sheds light on the citizenship(s) preceding it. When a professional experiences ethics as 'Citizenship of the wider world', they will experience ethics as 'Citizenship of my world' differently to a professional who is not experiencing ethics as 'Citizenship of the wider world'. In other words, each subsequent experience illuminates the previous experiences in a new way. For example, when a professional experiences ethics as 'Citizenship of my world', they may view altruistic acts as a means of salving their own conscience - 'you've got to be able to live with yourself, I guess, afterwards. It's all very selfish, really' (Participant 26) ${ }^{1}$ — whereas, when a professional experiences ethics as 'Citizenship of the wider world' they may view altruistic acts as fulfilling their responsibility towards other people - 'it's about what I want to achieve and what I think that I should be doing to contribute to society and mankind and whatever and I would rather have my skills used in an area which I think is ... better' (Participant 13). Therefore, the citizenships represent pervasive changes of perspective on the part of the professional.

The 'Model of Ethical IT', then, indicates a developing relationship between IT professionals and the world in which they work. The outward-looking axis represents ethical conduct at all points. As argued earlier, however, a professional who has a comprehensive experience of ethics will evidence in their practice all of the facets which lie along this axis.

The outer layers in this model influence professional practice at the inner layers. For example, professionals experiencing ethics as 'Citizenship of the wider world' are aware of their own needs, however, they intentionally set them aside for the sake of others; and, professionals who experience ethics as 'Citizenship of the client's world' are aware of the organisation's needs, however, they risk censure by challenging the corporation to accept additional expense for the client's sake. Thus, the wider world experience influences a professional's answer to the question: 'What if a client asks you to exploit other people on their

1 Quotes are of participants in research detailed in Stoodley $2009 \mathrm{~b}$. 
behalf?' The wider world experience also results in the professional including activities in their portfolio that offer no reimbursement, but which help meet the needs of the underprivileged.

\section{A conceptual tool}

The 'Model of Ethical IT' may be used as a tool to support education which strives to prompt an experiential change of ethics amongst IT professionals.

Throughout this chapter, we have presented a constitutionalist understanding of how knowledge is gained about the world. From this viewpoint, learners contribute to the experience of learning as much as the object of learning itself. The past experience of the learner and a circumstantial perception of relevance determine how they will understand their encounter with the phenomenon they are facing. This includes the IT professional's encounters with ethics.

From the point of view of a constitutionalist approach to knowledge, significant influence over people is exerted, not at a behavioural level, but at an experiential level. In other words, our influence over others is most effectively exerted in the realm of their relation to their circumstances.

Human behaviour is not controlled by structures, systems and prescriptions as such. Instead, it is how people understand those structures, systems and prescriptions that determine their behaviour. (Sandberg and Targama, 2007: 175)

Influence over an IT professional's practice of ethics is thus best instigated through influencing their conceptions of ethics. This changes an educating leader's role from one of controlling, to that of guiding and stimulating understanding.

For example, as previously noted, the enforcement of codes has been observed to exert an influence over employee behaviour. What, however, has such enforcement taught practitioners? The lessons learned may have been that the corporate environment is a punitive one; that the letter of the law is key and that if behaviour seems to conform to the law then that is sufficient. The enforcement of codes does not need to convey such lessons, however. To ensure these perceptions are not imparted, enforcement needs to be accompanied by meaningful communication concerning its significance.

The 'Model of Ethical IT' serves as a conceptual tool, to represent the relationships among people and artefacts in the IT space. It illustrates these relationships in a way that is readily grasped and easily remembered. A diagram 
can be more effective at conveying such conceptual information than written prose. The model, then, offers a means of interacting with IT professionals on an experiential level.

The model may be used, in a strategic sense, to orient activities towards certain goals or outcomes, or it may be used, in an operational sense, to evaluate specific actions. It may be usefully employed to:

- reconceptualise the IT professional space

- plan future directions

- provide guidance of ethical formation and support

- define the scope of the IT profession's ethical responsibility

- provide inspiration for individual and organisational guidelines

- set standards of conduct and aspiration

- aid communication between stakeholders.

This conceptual tool could be used on an individual, group, organisational, professional or discipline level. At the individual level, IT professionals may refer to it in order to conduct a self-assessment of their practice. At the group level, a learning facilitator may present it to a gathering of professionals as a prompt for discussion. At the organisational level, a corporation may use it as a yardstick against which to measure their goals. At the professional level, a professional body may consider it as they formulate visionary statements for their members. At the discipline level, disciplinary leaders may adopt it as a means of envisioning new conceptual connections and future directions.

Our conceptualisations of IT play a key role in the deployment of IT, determining our expectations of IT and the way we interact with IT. This indicates the potential power of such a model.

\section{A learning tool}

The model may be employed as a learning tool, to stimulate professionals to make the conceptual shifts that it represented. It would thus prompt professionals to enlarge their experience of ethics.

The insights into learning offered by variation theory indicate how powerful conceptual shifts may be deployed for the effective formation of professionals. Variation theory is a theory of learning derived from the approach taken in this research (phenomenography). It identifies the need to confront new ways of experiencing a phenomenon in order for effective learning to take place. That is, in order to understand the complexity of a phenomenon such as ethics, you 
need to experience the breadth of its complexity. If you are not offered the opportunity to understand the levels of complexity in the experience, then you cannot learn about it (Edwards, 2007). Therefore, the model presented here may be used as a curriculum guide, to ensure practitioners in formation have the opportunity to encounter all of these different ways of experiencing professional ethics.

Activities which apply the insights of variation theory, using the model to engender the expansion of the learner's experience, could include:

- presentation and discussion of the range of citizenships

- self-assessment of the learner's practice against the citizenships

- examination of case studies of IT professionals representing the range of citizenships

- involvement in practical projects which expose learners to the range of citizenships

- journaling of personal engagement with the citizenships.

The key differences between the citizenships lie in the practitioner's dual experience of rights and responsibilities. These aspects of the citizenships identify critically different perspectives out of which different behaviours proceed. They specify key educational turning points for ethical training and key elements of variation, which need to be intentionally brought into awareness.

Thus, three sources of opinion on IT ethics agree. IT professionals, Emmanuel Levinas (1998) and Daryl Koehn (1994) all demonstrate that the most significant variations in ethics are the nuances of relationship between the professional and others (Stoodley, 2009b). An emphasis on the diversity of possible relationships (as indicated in the citizenships) and personal reflection in the light of that diversity are central to the learning process.

Similar approaches to IT ethics education have been recommended by others. One suggestion has been the collaborative creation of a code of ethics that encourages a reflective and critical learning experience. It is signalled that this constructivist approach to education contrasts with the cognitivist educational approach which students typically encounter, so it may cause them some confusion. Thus, an early orientation of the learners to constructivism is necessary for them to gain the most for the experience (Stahl et al., 2004). This would also be true of a constitutionalist to bring differing points of view together in an environment where different stakeholders are forced to communicate and collaborate. This is proposed out of a moral development perspective forwarded by Rest (1986) in which exposure to complexity fosters development. Participating experienced 
IT professionals are expected to represent the accepted standard of ethical conduct against which students are able to measure their own ideas (Vartiainen, 2005a).

The central message of variation theory is the need to intentionally focus on variation of experience. The role of the instructor in variation theory is to ensure that the learner's experience is being expanded in ways that are potentially educationally meaningful. It is incumbent on the facilitator to determine what those educationally meaningful experiences are, a task which is aided by phenomenographic investigation which seeks to describe qualitatively different ways of experiencing phenomena (Stoodley, 2009b). This chapter provides a framework of the appropriate differences of experience for representation in a program of study of IT professional ethics. In other words, it is important that the learners be exposed to each of the citizenships. This does not necessarily need to occur in a progressive way, the main concern is that the learners have the possibility of meaningful contact with each citizenship. Nevertheless, systematic exposure to the citizenships could help learners grasp the expanding nature of the experiences represented by the citizenships.

The citizenship progression may also be used as the basis of a pre-test and posttest. This would draw the attention of learners to the citizenships, to the level of their identification with them and to the change in their relationship with them. A pre-test could serve the purpose of orienting learners to the core concepts of the citizenships and to their relationship with them. A post-test could serve the purpose of reminding learners of these aspects of ethics, of directing their attention to their relationship with them and of providing a means of selfassessing their change over the course of instruction. A subsequent question, in the light of these tests, such as 'How has your experience of ethics changed and does this appear to be a good thing?' may serve to prompt learners to reflect on any changes in their experience and whether those changes are desirable.

A short survey instrument could serve as a pre-test and post-test tool (for example, Figure 2). A strength of this instrument is that it could be rapidly administered and it would allow learners to situate their views incrementally in relation to the citizenships. A weakness is that it may lead their thoughts, for example, by framing their experience of ethics too strongly in terms of responsibility (and rights, which are implied in the statements) and by suggesting the 'correct' answers too obviously. In the light of this, it is probably useful to view this survey instrument at the pre-test stage not only as a means of eliciting the learner's views but also as a means of introducing them to the concepts that are central to the educational program on which they are embarking. 


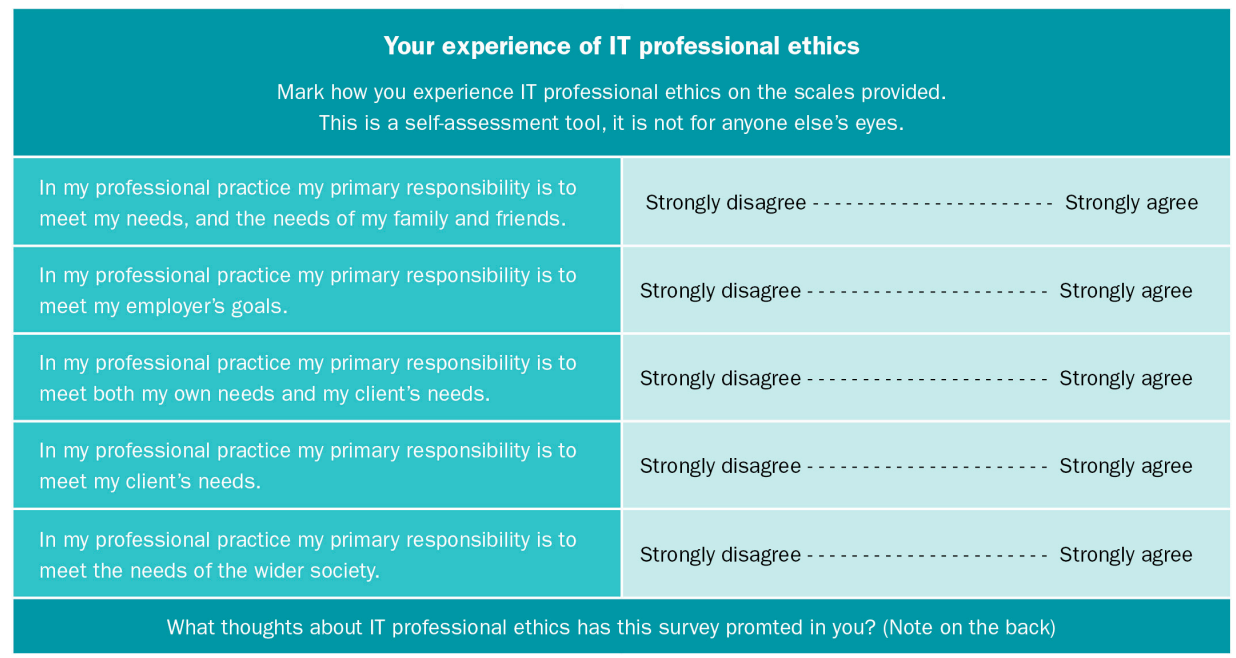

\section{Figure 2: A survey of learner's experiences of ethics}

Source: Author's research

The 'Model of Ethical IT', then, may serve as an overview of the citizenships. Such a model provides a means of encapsulating the main concepts succinctly and representing how they relate. The learners could be asked to devise their own model of ethical IT before viewing this model, then asked to compare and contrast the two models, and to provide a rationale for their preferences. This would serve the purpose of drawing their attention to the phenomenon of professional ethics on a global level and prompt their thoughts on the structural aspect of the experience of ethics. It would also provide a means of contact with learners who relate to diagrammatic representations of knowledge.

Evidence provided by phenomenography suggests that we all start at a global level and progressively situate details in accordance with our global understanding of the phenomenon of our attention (Marton \& Booth, 1997). This is the way we make sense of new experiences as we are confronted with them. For example, we will not learn to read and write if we do not first understand somewhat what it means to be literate. Similarly, an IT professional will not be able to make sense of the detail of ethics if they do not first have at least a partial understanding of what it means to be ethical.

A course of instruction based on the citizenships could, after an initial overview, concentrate on the citizenships one at a time. This would provide the opportunity to explore the meaning of each citizenship, the relevance of each to professional practice, how each would be expressed in daily work and how each is related to the others. 
A gambit of activities could serve to draw out the citizenship meanings - case studies, guest speakers, field visits, peer presentations and debates. In addition, in order to engage the learners on an experiential level, a practical project could be chosen by the learners, which would provide a stimulus for group discussion. For such a project to offer the range of citizenship experiences it could be conducted in collaboration with a local employer and be offered as a community service. Such a project could meet a community IT need. The effectiveness of reflection in professional development (Moon, 1999, 2006) indicates the appropriateness of the use of journaling in the learning process, through which the learners could consider their relationship with the citizenship continuum in the light of the demands of their practical project.

\section{Conclusion}

IT ethics education may be approached from various educational standpoints, resulting in different outcomes. We present here an additional approach to those predominantly espoused by IT ethicists to date. Educating for experiential change offers a means by which deep learning may occur, which will evidence itself in professional practice, to the benefit of the computing profession and the world which it impacts.

\section{Acknowledgements}

Various parts of this chapter are adapted from the report of a doctoral study on the experience of IT ethics (Stoodley, 2009a, 2009b).

\section{References}

ACS, 2012, ACS Code of ethics Case Studies \& related clauses of the code of conduct, viewed 6 February 2013 <http://www.acs.org.au/_data/assets/ pdf_file/0020/12179/ACS-Code-of-Ethics-Case-Studies.pdf $>$

Bowden, J \& Marton, F, 1998, The university of learning, Kogan Page, London.

Bruce, C, 1997, The seven faces of information literacy, Auslib Press, Adelaide.

Bynum, TW, 2004, 'Ethical decision-making and case analysis in computer ethics', in TW Bynum \& S Rogerson (eds), Computer ethics and professional responsibility, Blackwell, Malden, pp 60-86. 
Professionalism in the Information and Communication Technology Industry

Coady, M \& Bloch, S (eds), 1996, Codes of ethics and the professions, Melbourne University Press, Carlton South.

Colnerud, G, 2006, 'Teacher ethics as a research problem: syntheses achieved and new issues', Teachers \& Teaching, vol 12, no 3, pp 365-85.

Cronan, TP \& Douglas, DE, 2006, 'Toward a comprehensive ethical behavior model for information technology', Journal of Organizational and End User Computing, vol 18, no 1, pp i-xi.

Edwards, SL, 2007, 'Phenomenography: "Follow the yellow brick road!"', in $\mathrm{S}$ Lipu, K Williamson \& A Lloyd (eds), Exploring methods in information literacy research, Centre for Information Studies, Charles Sturt University, Wagga Wagga, pp 87-109.

Ferguson, S, Salmond, R, Al-Saggaf, Y, Bowern, M \& Weckert, J, 2005, 'Case studies and codes of ethics: the relevance of the ACS experience to ALIA', The Australian Library Journal, August, pp 299-308.

Gilligan, C, 1982, In a different voice: Psychological theory and women's development, Harvard University Press, Cambridge.

Goodpaster, KE, 1996, 'Praxiology and the moral agenda for professional education', Praxiology: The International Annual of Practical Philosophy \& Methodology, pp 437-53.

Greening, T, Kay, J \& Kummerfeld, B, 2004, 'Integrating ethical content into computing curricula', paper presented at the 6th Australasian Computing Education Conference, Dunedin, New Zealand.

Grodzinsky, FS, 1999, 'The practitioner from within: revisiting the virtues', Computers and Society, vol 29, no 1, pp 9-15.

_ 2000, "The development of the "ethical" ICT professional: and the vision of an ethical on-line society: how far have we come and where are we going?', Computers and Society, vol 30, no 1, pp 3-7.

Koehn, D, 1994, The ground of professional ethics, Routledge, London.

Kohlberg, L, 1981, Essays on moral development, Volume 1: the philosophy of moral development, Harper \& Row, San Francisco.

Leonard, LNK, Cronan, TP \& Kreie, J, 2004, 'What influences IT ethical behavior intentions - planned behavior, reasoned action, perceived importance, or individual characteristics?', Information \& Management, vol 42, pp 143-58. 
Levinas, E, 1998, Entre nous: on thinking-of-the-other, MB Smith \& B Harshav, trans, Athlone Press, London.

Maner, W, 2004, 'Unique ethical problems in information technology', in TW Bynum \& S Rogerson (eds), Computer ethics and professional responsibility, Blackwell, Malden, pp 39-59.

Marton, F \& Booth, S, 1997, Learning and awareness, Lawrence Erlbaum Associates, Mahwah, NJ.

Moon, JA, 1999, Reflection in learning \& professional development, Kogan Page, London.

— 2006, Learning journals: a handbook for reflective practice and professional development, Routledge, London.

Paradice, DB \& Dejoie, RM, 1991, 'The ethical decision-making processes of information systems workers', Journal of Business Ethics, vol 10, pp 1-21.

Ramsden, P, 1988, 'Studying learning: improving teaching', in P Ramsden (ed), Improving learning: new perspectives, Kogan Page, London, pp 13-31.

- 2003, Learning to teach in higher education, RoutledgeFalmer, London.

Rest, JR, 1986, Moral development: advances in research and theory, Praeger, New York.

- , Narvaez, D, Bebeau, M \& Thoma, SJ, 1999, Postconventional moral thinking: a neo-Kohlbergian approach, Lawrence Erlbaum Associates, Mahwah.

Sandberg, J, 1994, Human competence at work: an interpretative approach, BAS, Goteborg, Sweden.

\& Targama, A, 2007, Managing understanding in organisations, Sage, London.

Staehr, LJ \& Byrne, GJ, 2003, 'Using the Defining Issues Test for evaluating computer ethics teaching', IEEE Transactions on Education, vol 46, no 2, pp 229-34.

Stahl, BC, Wood, C \& Howley, R, 2004, 'Teaching professional issues in computing through the development of a student code of conduct', Ethicomp 2, viewed 6 February 2013, <http://www.cse.dmu.ac.uk/ bstahl/publications/2004_ professional_issues_ethicomp.pdf $>$

Stoodley, I, 2009a, 'IT professionals' experience of ethics and its implications for IT education', PhD thesis, Queensland University of Technology. 
— , 2009b, Professional ethics: The IT experience, VDM Verlag Dr Muller.

Svensson, L, 1997, 'Theoretical foundations of phenomenography', Higher Education Research \& Development, vol 16, no 2, pp 159-71.

Tavani, HT, 2004, Ethics and technology: ethical issues in an age of information and communication technology, John Wiley \& Sons, Hoboken.

Trigwell, K, 2000, 'A phenomenographic interview on phenomenography', in J Bowden \& E Walsh (eds), Phenomenography, RMIT Press, Melbourne, pp $62-82$.

Tronto, J, 1993, 'Beyond gender difference to a theory of care', in MJ Larrabee (ed), An ethic of care: feminist and interdisciplinary perspectives, Routledge, New York, pp 240-57.

Vartiainen, T, 2005a, 'Moral conflicts in a project course in information systems education', PhD thesis, University of Jyväskylä, Finland.

- 2005b, 'Morally successful collaboration between academia and industry - a case of a project course', paper presented at the 14th International Conference on Information Systems Development, Karlstad, Sweden.

Woodward, B, Davis, D \& Hodis, F, 2007, 'The relationship between ethical decision making and ethical reasoning in information technology students', Journal of Information Systems Education, vol 18, no 2, pp 193-202. 